\section{Association of ADH1 and DDR48 expression with azole resistance in Candida albicans}

\section{Abstract}

Background: Candida albicans is a frequent opportunistic pathogenic fungus that causes mucosal and systemic infections. The alcohol dehydrogenase $1(A D H 1)$ and DDR48 genes were found to be upregulated in fluconazole resistant Candida albicans. Therefore, understanding the function of drug resistance of genes will help in the development of new antifungal agents that can reverse drug resistance. This study aimed to investigate the role of $A D H 1$ and DDR48 genes in development of fluconazole resistant $C$. albicans.

Subjects and Methods: This study involved 19 fluconazole susceptible and 6 fluconazole resistant $C$. albicans isolates from clinical specimens. The MICs of fluconazole were determined by the E-test. Quantitative expressions of Candida Drug Resistance (ADH1, CDR1, DDR48 and FLU1) genes were assessed by real time PCR.

Results: There was a statistically significant higher expression levels of CDR1, FLU1, ADH1 and DDR48 in resistant and susceptible dose dependent isolates than in susceptible isolates $(P=0.009,0.008$, $0.01,0.014$ respectively). Strong positive correlations were observed between the expression levels of each of $A D H 1$ and DDR4 with azole resistance genes CDR1 and $F L U 1[(\mathrm{rs})=0.945,0.815$, respectively; $P<0.001$; Spearman's $(\mathrm{rs})=0.852$ and 0.76 , respectively; $P<0.001$ ].

Conclusion: This is the first study that showed positive correlation between $D D R 48$ and azole resistance genes. It has also indicated that $A D H 1$ and DDR48 are associated with the resistance mechanisms of C. albicans to fluconazole. Identification of new drugs that target the
Marwa Salah Mostafa and Alaa Reda Awad

Department of Medical Microbiology and Immunology, faculty of medicine, Cairo University, Egypt

Corresponding author:

\section{Marwa Salah Mostafa}

झ marwa75_jan@yahoo.com 
proteins encoded by these genes will help in eradication of fluconazole resistant $C$. albicans in infection.

Keywords: fluconazole resistance, C. albicans, ADH1, DDR48, CDR1, FLU1genes.

\section{Introduction}

Candida albicans is a human fungal pathogen that causes serious infections in immunocompromised population [1]. In hospitalized patients, this organism can disseminate hematogenously and infect virtually all organs [2]. Fluconazole and other azoles enter C. albicans cells by facilitated diffusion [3]. These antifungal drugs inhibit cytochrome P450 enzymes: lanosterol demethylase, a key enzyme in ergosterol biosynthesis [4], and C-22 sterol desaturase [5].

C. albicans is becoming increasingly resistant to azole antifungal agents, particularly fluconazole, a problem of growing importance due to the widespread use of a limited number of antifungal agents, particularly azoles [6, 7]. Various mechanisms can lead to the acquired resistance of Candida spp. to azole drugs, and most involve the induction of the efflux pumps encoded by CDR (Candida Drug Resistance) or MDR (Multiple Drug Resistance) genes, or the over-expression or acquisition of point mutations in the gene encoding the target enzyme lanosterol demethylase [8]. Over-expression of drug-efflux pumps Cdr1, Cdr2 and Mdr1 has been linked to fluconazole resistance [9].

Multidrug efflux transporters of the $A B C$ (ATP-binding cassette) superfamily and of the Major Facilitator Superfamily (MFS) play a key role in the low level of accumulation of azoles in the yeast cell [10].
The $A B C$ transporter superfamily, including $C d r 1$ and $\mathrm{Cdr} 2$, are membrane proteins that have two membrane-spanning domains and two nucleotidebinding domains that utilize ATP to drive substrates across the membrane [11]. CDR1 and CDR2 genes have been shown to be upregulated in resistant strains, leading to an enhanced efflux of the drug [10] and hence leading to resistance to multiple azoles [12, 13]. Cross-resistance between fluconazole and other azoles has been reported [14-16], the mechanistic basis for this cross-resistance most often involves the upregulation of genes encoding the CDR pumps that act as ATP-binding cassette efflux transporters $[13,17,18]$.

On the other hand, MFS drug pumps, including Mdr1 and Flu1, have no nucleotide-binding domain but instead use the proton motive force of the membrane as an energy source [11]. Both MDR1 and FLU1 genes were over-expressed specifically in fluconazole-resistant C. albicans isolates. Disruption of FLU1 gene in C. albicans mutants with deletions in multidrug efflux transporter genes, including CDR1, CDR2 and MDR1, resulted in enhanced susceptibility to several azole derivatives, indicating the contribution of FLU1 in azole resistance [19].

The Adh1p (alcohol dehydrogenase protein) which is encoded by the $A D H 1$ gene, plays an important role in intracellular energy metabolism [20], as the most critical mechanism governing drug resistance 
in C. albicans entails the Cdr1p and Cdr2p efflux pump proteins, the functionality of which depends on energy metabolism $[19,21]$.

Another gene (DDR48) acts as cell stress gene that is involved in combating the effects of nitric oxide and in DNA repair [22]. A study reported that $D D R 48$ is upregulated in azole resistant C. albicans than in the sensitive isolates [23]. The relationship between the expression of $A D H 1$ and DDR48 with drug resistance in $C$. albicans requires further research. Understanding the resistance mechanisms and the associated drug resistance genes will help in the development of new antifungal agents that can reverse drug resistance.

The aim of this study is to investigate the expression of $A D H 1$ and DDR48 genes in fluconazole resistant C. albicans, and to assess the correlation between the expression levels of these genes and the expression of the azole resistance genes CDR1 and FLU1.

\section{Materials and Methods}

\section{Sample collection}

This study involved 25 C. albicans clinical isolates. Twenty strains were isolated from patients with vulvovaginal candidiasis and five strains were isolated from patients with respiratory infections. The isolates were collected from patients attending the outpatient clinics of Gynecology and Obstetrics department and patients admitted at Chest department in Kasr Al-Aini Hospitals, Cairo University, Egypt. All laboratory tests were carried out in the department of Medical Microbiology and Immunology, and the department of Biochemistry, Faculty of Medicine, Cairo University during the period from June 2013 to August 2014. The study protocol was approved by the Scientific Ethical Committee at Cairo University Hospitals and informed consent was obtained from each patient. All C. albicans isolates were identified by germ tube test, culture on ChromID Candida (Biomerieux, France) and by API C20 identification kit (Biomerieux, France).

\section{Fluconazole disk diffusion susceptibility testing}

Fresh subcultures of C. albicans isolates were prepared on SDA (Sabouraud dextrose agar). Fluconazole susceptibility was tested by using 25-ug fluconazole disks (Biorad, USA) on Mueller-Hinton agar supplemented with $2 \%$ glucose and $0.5 \mathrm{mg} / \mathrm{L}$ methylene blue inoculated with $0.5 \mathrm{McFarland}$ standard of an inoculum prepared in sterile $0.9 \% \mathrm{NaCl}$ [24]. The zone diameter was measured after 24 hours. Isolates with zone diameter of $\geq 19 \mathrm{~mm}$ were considered susceptible, those with zone diameter of 15 to $18 \mathrm{~mm}$ were considered susceptible dose-dependent, and those with zone diameter $\leq 14 \mathrm{~mm}$ were considered resistant [24, 25].

\section{Minimum inhibitory concentration (MIC) of fluconazole}

C. albicans isolates were subcultured on SDA and an inoculum was prepared in sterile $0.9 \% \mathrm{NaCl}$, adjusting the cell density to $0.5 \mathrm{McFarland}$ standard. The MIC of fluconazole was determined by E-test (AB BIODISK,Solna, Sweden) using Muller Hinton agar supplemented with $2 \%$ glucose and $0.5 \mathrm{mg} / \mathrm{L}$ methylene blue [24]. The MICs were read after 24 hours. Susceptible, susceptible dose-dependent and resistant isolates were defined by MICs of $\leq 8 \mathrm{mg} / \mathrm{L}$, 16 to $32 \mathrm{mg} / \mathrm{L}$ and $\geq 64 \mathrm{mg} / \mathrm{L}$ respectively $[24,25]$.

\section{Total RNA isolation}

C. albicans isolates were grown overnight at $37^{\circ} \mathrm{C}$ on SDA. Three to four colonies were suspended in phosphate buffer saline. Total RNA was isolated with RNeasy Mini Kit (Qiagen, USA) according to the man- 
ufacturer's protocol and further analyzed for quantity and quality using Beckman dual spectrophotometer (USA). The OD260 and OD280 values were measured, and the ratios were found to be 1.8-2.0. The RNA integrity was assessed by RT-PCR measurement of CaYST1- mRNA (C. albicans housekeeping gene) gene expression as the quality control.

\section{Real Time PCR for quantitative expression of ADH1, CDR1, DDR48 and FLU1 genes}

The mRNA expression level was measured by qRTPCR (quantitative reverse transcription polymerase chain reaction). Briefly, $1000 \mathrm{ng}$ of the total RNA from each sample were used for cDNA synthesis by reverse transcription using High capacity CDNA Reverse Transcriptase kit (Applied Biosystem, USA). The cDNA was subsequently amplified with the Syber Green I PCR Master Kit (Fermentas, Germany) using an Applied Biosystem with software version 3.1 (StepOne ${ }^{\mathrm{TM}}$, USA) as follows: 10 minutes at $95^{\circ} \mathrm{C}$ for enzyme activation followed by 40 cycles of 15 seconds at $95^{\circ} \mathrm{C}, 20$ seconds at $55^{\circ} \mathrm{C}$ and 30 second at $72^{\circ} \mathrm{C}$ for the amplification step. We used $1 \mu \mathrm{M}$ of both primers specific for each target gene. The threshold cycle $\left(C_{t}\right)$ value of CaYST1 was sub- tracted from that of the gene of interest to obtain a $\triangle C T$ value. The strain with the lowest $\triangle C T$ value for ADH1 was used as the baseline control strain, and the expression levels of the other strains were quantified relative to that of the control strain. Finally, RQ (relative quantity) expression level for each target gene was assessed relative to the calibrator and was expressed as $2-\Delta \Delta C T$. Primers sequences specific for each target gene are demonstrated in table 1.

\section{Statistical Analysis}

Data were analyzed using SPSS version 16 . The results were expressed as means \pm standard deviation (SD). The relative mRNA expression levels of $A D H 1$, CDR1, FLU1 and DDR48 in the susceptible and resistant isolates were compared using the independent samples $\mathrm{t}$ test, Kruskal Wallis $\mathrm{H}$ test was used to compare the relative mRNA expression levels of $A D H 1, C D R 1, F L U 1$ and DDR48 in the susceptible, susceptible dose dependent and resistant isolates. Spearman's rho (rs) was used for the analysis of correlation between the mRNA expression levels of the four studied genes. Statistical significance was defined at $P \leq 0.05$.

Table 1. Sequences of the gene-specific primers for amplification of the studied genes

\begin{tabular}{|c|c|c|}
\hline Gene & Primer sequence $5^{\prime}-3^{\prime}$ & Gene bank accession number \\
\hline $\mathrm{ADH} 1$ & $\begin{array}{l}\text { 5'- TGT CTG GTT ACA CTC ACG ATG G -3' } \\
\text { 5'- GCA TCG AAA ACT GGA GCA GT -3' }\end{array}$ & XM_002420714.1 \\
\hline CDR1 & $\begin{array}{l}\text { 5'- CTT AGT CAA ACC ACT GGA TCG -3' } \\
5^{\prime}-\text { CCA AAA GTG ATG AAA AGG C - -3' }\end{array}$ & XM_718116.1 \\
\hline FLU1 & $\begin{array}{l}\text { 5'- TGT TGC CTT TGA TGG TCC CG -3' } \\
5^{\prime}-\text { ACC GAT AAG GCA GCA AGA CC -3' }\end{array}$ & XM_715807.1 \\
\hline DDR48 & $\begin{array}{l}\text { 5'- TTT CGG TTT CGG TAA AGA CG -3' } \\
\text { 5'- TGA GTC GGT CTT GGA GGA AC -3' }\end{array}$ & XM_709160.1 \\
\hline CaYST1 & $\begin{array}{l}\text { 5'- AAGTATTTGGGAGAAGGGA-AAGGG -3' } \\
\text { 5'- AAAATGGGCATTAAGGA-AAAGAGC -3' }\end{array}$ & AJ251858.1 \\
\hline
\end{tabular}




\section{Results}

\section{Fluconazole susceptibility of the} C. albicans isolates

Fluconazole susceptibility testing revealed that 19 out 25 isolates were susceptible to fluconazole by both disk diffusion method and E-test (zone diameter $\geq 19$; MIC $\leq 8 \mathrm{mg} / \mathrm{L}$ ), and one isolate was resistant by both tests (zone diameter $\leq 14$; MICs $\geq 64$ $\mathrm{mg} / \mathrm{L}$ ). The remaining 5 isolates showed discrepancy between disk diffusion and $\mathrm{E}$ test results, they were fluconazole resistant by disk diffusion, however by the $E$ test, 2 of them were susceptible and 3 were susceptible dose-dependent (MIC $=24 \mathrm{mg} / \mathrm{L}$ ). Those 5 isolates had high expression levels of CDR1 and FLU1 azole resistance genes as well as $A D H 1$ and DDR48 genes.

\section{Expression of the studied genes among fluconazole susceptible and resistant C. albicans isolates}

Both the results of the disk diffusion, fluconazole resistant $C$. albicans isolates had significantly higher expression levels of $A D H 1, C D R 1, F L U 1$ and DDR48 genes than fluconazole susceptible $C$ albicans iso- lates. Table 2 shows the means, standard deviations and P-values of the expression levels of the four studied genes among fluconazole resistant and susceptible Candida albicans isolates.

Comparing the expression levels of the studied genes among $\mathrm{C}$. albicans isolates based on the Etest results by Kruskal-Wallis $\mathrm{H}$ test revealed statistically significant higher expression levels of CDR1, FLU1, ADH1 and DDR48 in susceptible dose dependent and resistant isolates compared to susceptible ones, data are shown in table $\mathbf{3}$.

\section{Correlation between expression of $A D H 1$ and DDR48 with azole resistance genes}

There were strong positive correlations among all 25 clinical C. albicans isolates between the relative mRNA expression levels of $A D H 1$ and the azole resistance genes CDR1 and FLU1 (rs) $=0.945,0.815$, respectively; $P<0.001$ ) (Table 4).

Strong positive correlations were also observed between the relative mRNA expression levels of $D D R 48$ and each of CDR1 and FLU1 (rs) $=0.852$ and 0.76, respectively; $P<0.001$ ) (Table 4).

Table 2. Expression levels of the four studied genes among fluconazole resistant and fluconazole susceptible C. albicans isolates

\begin{tabular}{|c|c|c|c|c|c|}
\hline & \multicolumn{2}{|c|}{$\begin{array}{l}\text { Fluconazole susceptible } \\
\qquad n=19\end{array}$} & \multicolumn{2}{|c|}{$\begin{array}{l}\text { Fluconazole Resistant } \\
\qquad \mathrm{n}=6\end{array}$} & \multirow[t]{2}{*}{ P-value } \\
\hline & Mean & SD & Mean & $S D$ & \\
\hline $\mathrm{ADH} 1$ & 3.32 & 1.7 & 12.11 & 2.0 & $<0.001$ \\
\hline CDR1 & 2.28 & 1.3 & 10.34 & 2.09 & $<0.001$ \\
\hline FLU1 & 2.09 & 1.14 & 7.93 & 0.89 & $<0.001$ \\
\hline DDR48 & 2.71 & 1.19 & 8.4 & 3.36 & 0.008 \\
\hline
\end{tabular}


Table 3. Comparing the expression levels of the four studied genes among C. albicans isolates based on the E-test results

\begin{tabular}{|c|c|c|c|c|}
\hline & Fluconazole E-test & $\mathbf{N}$ & Mean Rank & P-value \\
\hline \multirow{3}{*}{ CDR1 } & Susceptible & 21 & 11.05 & 0.009 \\
\hline & Susceptible dose dependent & 3 & 22.67 & \\
\hline & Resistant & 1 & 25.00 & \\
\hline \multirow{3}{*}{ FLU1 } & Susceptible & 21 & 11.00 & 0.008 \\
\hline & Susceptible dose dependent & 3 & 23.67 & \\
\hline & Resistant & 1 & 23.00 & \\
\hline \multirow{3}{*}{ ADH1 } & Susceptible & 21 & 11.05 & 0.01 \\
\hline & Susceptible dose dependent & 3 & 22.67 & \\
\hline & Resistant & 1 & 25.00 & \\
\hline \multirow{3}{*}{ DDR48 } & Susceptible & 21 & 11.14 & 0.014 \\
\hline & Susceptible dose dependent & 3 & 22.00 & \\
\hline & Resistant & 1 & 25.00 & \\
\hline
\end{tabular}

Table 4. Correlation of the mRNA expression levels of $A D H 1$ and DDR48 to azole resistance genes CDR1 and FLU1

\begin{tabular}{|c|c|c|c|}
\hline \multirow[t]{2}{*}{ Gene } & \multirow[t]{2}{*}{ Mean $\pm S D$} & $\begin{array}{l}\left.\text { Spearman's rho ( } r_{s}\right) \\
\text { Correlation Coefficient to ADH1 }\end{array}$ & $\begin{array}{l}\text { Spearman's rho }\left(r_{s}\right) \\
\text { Correlation Coefficient to DDR48 }\end{array}$ \\
\hline & & $5.43 \pm 4.20$ & $4.07 \pm 3.09$ \\
\hline CDR1 & $4.21 \pm 3.81$ & $0.945^{*}$ & $0.852^{*}$ \\
\hline FLU1 & $3.5 \pm 2.76$ & $0.815^{\star}$ & $0.760 *$ \\
\hline
\end{tabular}

\section{Discussion}

\section{Fluconazole susceptibility of $C$. albicans} isolates

Nineteen C. albicans isolates were fluconazole susceptible and one isolate was resistant by both disk diffusion and the E-test. The remaining five isolates were found resistant by disk diffusion, susceptible or susceptible dose-dependent by the E-test. These
5 isolates had high expression levels of azole resistance CDR1, FLU1 genes as well as with $A D H 1$ and DDR48 genes.

Previous studies reported discrepancy between fluconazole disk diffusion and E-test, although Torres and colleagues (2009) reported a positive correlation between disk diffusion method and the E-test. They observed that one Candida isolate was resistant to fluconazole by disk diffusion but susceptible 
by the E-test [26]. Furthermore, a study by Vandenbossche and colleagues (2002) reported that one $C$. tropicalis strain, with $\mathrm{MIC}>256 \mathrm{mg} / \mathrm{L}$ was observed to be susceptible by the E-test $(\mathrm{MIC}=0.5$ $\mathrm{mg} / \mathrm{L}$ ) using broth macro-dilution method [27]. The agreement between the E-test and macro-dilution method ranged from $87-100 \%$ within two dilutions for Candida spp. In general, there was a tendency to read the E-test MICs slightly lower than macro- and micro-dilution methods [27-29]. It is worth mentioning that fluconazole susceptibility testing of C. albicans using the E-test technique is difficult to interpret due to the fact that scattered inner colonies can make the inhibition zones difficult to read, a phenomenon called trailing endpoints [28-31]. Presence of trailing in Candida isolates, although susceptible to fluconazole, means express the same molecular mechanisms as SDD and resistant isolates following fluconazole exposure [32]. Therefore, molecular tools should become the gold standard for the identification of Candida drug resistance. Interestingly, the five isolates, that were resistant by disk diffusion and susceptible or susceptible dosedependent by the E-test, had high expression levels for tested azole resistance genes (CDR1, FLU1, ADH1 and DDR48).

\section{Expression of the studied genes among fluconazole susceptible and resistant C. albicans isolates}

The present study showed significantly higher expression levels of CDR1, FLU1, ADH1 and DDR48 genes in fluconazole resistant than in fluconazole susceptible $C$. albicans isolates. These results are in concordance with a study by Guo et al. (2013) who reported that $A D H 1, C D R 1$ and FLU1 were highly expressed in the resistant $C$. albicans isolated from patients with vulvovaginal candidiasis than in susceptible dose-dependent isolates. They also reported a significant positive correlation between the expression of $A D H 1$ and the MICs of fluconazole
[33]. On the other hand, Siikala et al. (2011) demonstrated a negative correlation between the relative expressions of $A D H 1$ and each of $C D R 1$ and $C D R 2$ in C. albicans isolated from autoimmune polyendocrinopathy-candidosis-ectodermal dystrophy patients. They also observed no correlation between the expression levels of $A D H 1$ and the MICs of fluconazole. They conferred these results to metabolic changes in the isolates. For example: catabolite repression leading to $A D H$ repression which could induce CDRs in their patients [34].

\section{Correlation between ADH1 and the azole resistance genes expression}

In this study, there were strong positive correlations between the relative mRNA expression levels of $A D H 1$ and the azole resistance genes CDR1 and FLU1 (Spearman's $\left(r_{s}\right)=0.945,0.815$, respectively; $P<0.001)$. Similarly, Guo et al. (2013) reported that the expression of the $A D H 1$ gene was positively correlated with the expression of the azole resistanceassociated genes CDR1 and FLU1, indicating that high ADH1 mRNA expression is closely correlated to drug resistance in C. albicans [33].

Adh1p is involved in glycolysis, which is the major metabolic reaction under anoxic conditions in yeast, and is responsible for most of the alcohol dehydrogenase activity in yeast [35]. The high expression of the $A D H 1$ gene is likely plays a role in promoting drug resistance in C. albicans. Elevated $A D H 1$ gene expression may signify the activation of the glycolysis pathway, which can result in enhanced ATP generation. Thus, more energy is produced for the drug efflux pump located in the $C$. albicans cell membrane, leading to the export of azole drugs and a decrease in the intracellular accumulation of these drugs, and results in drug resistance [33]. Furthermore, the Adh1p was found to be upregulated at the protein level in fluconazole resistant $C$. albicans $[36,37]$. 


\section{Correlation between DDR48 gene expression and azole-resistance genes}

There were also strong positive correlations between the relative mRNA expression levels of DDR48 and each of CDR1 and FLU1 (Spearman's $\left(r_{s}\right)=0.852$ and 0.76 , respectively; $P<0.001$ ). Barker et al. (2004) reported that the expression of the cell stress gene DDR48, a member of a set of genes that displays increased transcription in response to DNA lesions, heat-shock stress [38], and in C. albicans biofilms [39], was up-regulated by 7.4 fold in the azole resistant $C$. albicans isolate than in the sensitive one [23]. Cleary et al. (2012) demonstrated a role for DDR48 in sensing or responding to environmental nutritional conditions, they concluded that this protein has an important influence on pathogenesis [40]. Furthermore, DDR48 mutant strain generated in a study by Dib et al. (2008) was susceptible in a dose-dependent manner to fluconazole and itraconazole compared with the resistant parent strain that possesses DDR48 gene [41]. Previous data also showed that exposure to fluconazole and itraconazole led to increased expression of DDR48 RNA [42]. It is worth pointing out that the importance of DDR48 for filamentation, stress response and biofilm formation highlights its role in virulence and makes it a prime target for antifungal drug design [41]. Interestingly, our results indicate that the correlation of $A D H 1$ was higher than that of $D D R 48$ to azole resistance genes, suggesting that the $A D H 1$ gene has more crucial role and is more reliable in detecting azole resistance in C. albicans.

In conclusion, the mRNA expression levels of $A D H 1$ and DDR48 had strong positive correlation with the expression levels of CDR1 and FLU1 azole resistance genes. Furthermore, $A D H 1$ and DDR48 expression levels were significantly higher in fluconazole resistant than in fluconazole susceptible $C$. albicans clinical isolates. These results indicate that these genes have an important role in the resistance mechanisms of $C$. albicans to fluconazole and probably to other azoles. Identification of new drugs that target the proteins encoded by these genes will help in eradication of fluconazole resistant $C$. albicans during infection. To our knowledge, this is the first study that investigates the association between DDR48 and azole resistance genes. Further research is required to clarify the role of DDR48 in drug resistance mechanisms. However, the role of $A D H 1$ seems to be more crucial in azole resistance in C. albicans.

\section{There is no conflict of interest}

\section{References}

1. Shapiro RS, Robbins N, Cowen LE. Regulatory circuitry governing fungal development, drug resistance, and disease. Microbiol Mol Biol Rev 2011; 75: 213-67.

2. Wisplinghoff $H$, Bischoff $T$, Tallent SM, Seifert $H$, Wenzel $\mathrm{RP}$, Edmond MB. Nosocomial bloodstream infections in US hospitals: analysis of 24,179 cases from a prospective nationwide surveillance study. Clin Infect Dis 2004; 39: 309-17.

3. Mansfield BE, Oltean HN, Oliver BG, Hoot SJ, Leyde SE, Hedstrom L, White TC. Azole drugs are imported by facilitated diffusion in Candida albicans and other pathogenic fungi. PLoS Pathog 2010; 6(9): e1001126.

4. Morschhaüser J. The genetic basis of fluconazole resistance development in Candida albicans. Biochimica Biophysica Acta 2002; 1587: 240-8.

5. Lamb DC, Maspahy S, Kelly DE, Manning NJ, Geber A, Bennett JE, Kelly SL. Purification, reconstitution, and inhibition of cytochrome P-450 sterol delta22-desaturase from the pathogenic fungus Candida glabrata. Antimicrob Agents Chemother 1999: 43: 1725-8.

6. Alexander BD, Perfect JR. Antifungal resistance trends towards the year 2000. Implications for therapy and new approaches. Drugs 1997; 54: 657-78.

7. Rex JH, Pfaller MA. Has antifungal susceptibility testing come of age? Clin Infect Dis 2002; 35: 982-9.

8. Pfaller MA. Antifungal drug resistance: mechanisms, epidemiology, and consequences for treatment. Am J Med 2012; 125: S3-S13.

9. Park S, Perlin DS. Establishing Surrogate Markers for Fluconazole. Microb Drug Resist 2005; 11(3): 232-8.

10. Sanglard D, Kuchler K, Ischer F, Pagani JL, Monod M, Bille J. Mechanisms of resistance to azole antifungal agents in Candida albicans isolates from AIDS patients involve specific multidrug transporters. Antimicrob Agents Chemother 1995; 39: 2378-86. 
11. Cannon RD, Lamping E, Holmes AR, Niimi K, Baret PV, Keniya MV, Tanabe K, Niimi M, Goffeau A, Monk BC. Efflux-mediated antifungal drug resistance. Clin Microbiol Rev 2009; 22: 291 321.

12. Borst A, Raimer MT, Warnock DW, Morrison CJ, ArthingtonSkaggs BA. Rapid acquisition of stable azole resistance by Candida glabrata isolates obtained before the clinical introduction of fluconazole. Antimicrob Agents Chemother 2005; 49(2): 783-7.

13. Sanguinetti M, Posteraro B, Fiori B, Ranno S, Torelli R, Fadda G. Mechanisms of azole resistance in clinical isolates of Candida glabrata collected during a hospital survey of antifungal resistance. Antimicrob Agents Chemother 2005; 49(2): 66879.

14. Pfaller MA, Diekema DJ, Jones RN, Messer SA, Hollis RJ; SENTRY Participants Group. Trends in antifungal susceptibility of Candida spp. from pediatric and adult patients with bloodstream infections: SENTRY Antimicrobial Surveillance Program, 1997 to 2000. J Clin Microbiol 2002; 40(3): 852-6.

15. Ostrosky-Zeichner L, Rex JH, Pappas PG, Hamill RJ, Larsen RA, Horowitz HW, Powderly WG, Hyslop N, Kauffman CA, Cleary J,Mangino JE, Lee J. Antifungal susceptibility survey of 2,000 bloodstream candida isolates in the United States. Antimicrob Agents Chemother 2003; 47(10): 3149-54.

16. Pfaller MA, Boyken L, Messer SA, Tendolkar S, Hollis RJ, Diekema DJ. Comparison of results of voriconazole disk diffusion testing for Candida species with results from a central reference laboratory in the ARTEMIS Global Antifungal Surveillance Program. J Clin Microbiol 2005; 43(10): 5209-13.

17. Sanglard D, Ischer F, Monod M, Bille J. Cloning of Candida albicans genes conferring resistance to azole antifungal agents: characterization of CDR2, a new multidrug $A B C$ transporter gene. Microbiology 1997; 143: 405-16.

18. Sanglard D, Ischer F, Koymans $L$, Bille J. Amino acid substitutions in the cytochrome P-450 lanosterol 14 $\alpha$-demethylase (CYP51A1) from azole-resistant Candida albicans clinical isolates contribute to resistance to azole antifungal agents. Antimicrob Agents Chemother 1998; 42(2): 241- 53.

19. Chen LM, Xu YH, Zhou CL, Zhao J, Li CY, Wang R. Overexpression of CDR1 and CDR2 genes plays an important role in fluconazole resistance in Candida albicans with G487T and T916C mutations. J Int Med Res 2010; 38(2): 536-45.

20. Bertram G, Swoboda RK, Gooday GW, Gow NA, Brown AJ. Structure and regulation of the Candida albicans ADH1 gene encoding an immunogenic alcohol dehydrogenase. Yeast 1996; 12(2): 115-27.

21. Li R, Kumar R, Tati S, Puri S, Edgerton M. Candida albicans Flu1 mediated efflux of salivary Histatin 5 reduces its cytosolic concentration and fungicidal activity. Antimicrob Agents Chemother 2013; 57(4): 1832-9.

22. Hromatka BS, Noble SM, Johnson AD. Transcriptional response of Candida albicans to nitric oxide and the role of the YHB1 gene in nitrosative stress and virulence. Mol Biol Cell 2005; 16(10): 4814-26

23. Barker KS, Crisp S, Wiederhold N, Lewis RE, Bareither B, Eckstein J, Barbuch R, Bard M, Rogers PD. Genome-wide expression profiling reveals genes associated with amphotericin B and fluconazole resistance in experimentally induced antifungal resistant isolates of Candida albicans, J Antimicrob Chemother 2004; 54(2): 376-85

24. Clinical and Laboratory Standards Institute. Method for antifungal disk diffusion susceptibility testing of yeasts: approved guideline-second edition M44-A2. CLSI, Wayne, PA, USA, 2009.

25. Pfaller MA, Diekema DJ, Sheehan DJ. Interpretive Breakpoints for Fluconazole and Candida Revisited: a Blueprint for the Future of Antifungal Susceptibility Testing. Clin Microbiol Rev 2006; 19(2): 435-47.

26. Torres DNA, Alvarez MCA, Rondón SMA. Fluconazole susceptibility of invasive Candida spp. isolates as determined by three methods: Bogotá - Colombia. Rev Chilena Infectol 2009; 26(2): 135-43

27. Vandenbossche I, Vaneechoutte $M$, Vandevenne $M$, De Baere $T$, Verschraegen $G$. Susceptibility testing of fluconazole by the NCCLS broth macrodilution method, E-test, and disk diffusion for application in the routine laboratory. J Clin Microbiol 2002; 40(3): 918-21.

28. Chen SC, O'Donnell ML, Gordon S, Gilbert GL. Antifungal susceptibility testing using the E-test: comparison with the broth macrodilution technique. J Antimicrob Chemother 1996; 37(2): 265-73

29. Matar MJ, Ostrosky-Zeichner L, Paetznick VL, Rodriguez JR, Chen E, Rex JH. Correlation between E-test, disk diffusion, and microdilution methods for antifungal susceptibility testing of fluconazole and voriconazole. Antimicrob Agents Chemother 2003; 47(5): 1647-51.

30. Pfaller MA, Messer SA, Karlsson A, Bolmström A. Evaluation of the E-test method for determining fluconazole susceptibilities of 402 clinical yeast isolates by using three different agar media. J Clin Microbiol 1998; 36(9): 2586-9.

31. Tapia $C$, León E, Palavecino E. Antifungal susceptibility of yeasts by E-test. Comparison of 3 media. Rev Med Chil 2003; 131(3): 299-302.

32. Lee MK, Williams LE, Warnock DW, Arthington-Skaggs BA. Drug resistance genes and trailing growth in Candida albicans isolates. J Antimicrob Chemother 2004; 53(2): 217-24.

33. Guo H, Zhang XL, Gao LQ, Li SX, Song YJ, Zhang H. Alcohol dehydrogenase I expression correlates with CDR1, CDR2 and FLU1 expression in Candida albicans from patients with vulvovaginal candidiasis, Chin Med J 2013; 126(11): 2098102.

34. Siikala $E$, Bowyer $P$, Richardson $M$, Saxen $H$, Sanglard $D$, Rautemaa R. ADH1 expression inversely correlates with CDR1 and CDR2 in Candida albicans from chronic oral candidosis in APECED (APS-I) patients. FEMS Yeast Research 2011; 11(6): 494-8.

35. Leskovac V, Trivié S, Pericin D. The three zinc-containing alcohol dehydrogenases from baker's yeast, Saccharomyces cerevisiae. FEMS Yeast Res 2002; 2(4): 481-94.

36. Yan L, Zhang JD, Cao YB, Gao PH, Jiang YY. Proteomic analysis reveals a metabolism shift in a laboratory fluconazole-resistant Candida albicans strain. J Proteome Res 2007; 6: 2248- 56. 
37. Wang Z, Zhang G, Zhang $X$, Wu S, Yin $X$, Hong Zhang $H$. Proteomic analysis of fluconazole resistance in Candida albicans. Afr J Pharm Pharmaco 2012; 6(16): 1226-30.

38. Treger JM, McEntee K. Structure of the DNA damage-inducible gene DDR48 and evidence for its role in mutagenesisin Saccharomyces cerevisiae. Mol Cell Biol 1990; 10(6): 3174-84.

39. Thomas DP, Pitarch A, Monteoliva L, Gil C, Lopez-Ribot JL. Proteomics to study Candida albicans biology and pathogenicity. Infect Disord Drug Targets 2006; 6(4): 335-41.

40. Cleary IA, MacGregor NB, Saville SP, Thomas DP. Investigating the function of Ddr48p in Candida albicans. Eukaryot Cell 2012; 11(6): 718-24.

41. Dib L, Hayek P, Sadek H, Beyrouthy B, Khalaf RA. The Candida albicans Ddr48 protein is essential for filamentation, stress response, and confers partial antifungal drug resistance. Med Sci Monit 2008; 14(6): BR113-21.

42. Rogers PD, Barker KS. Genome-wide expression profile analysis reveals coordinately regulated genes associated with stepwise acquisition of azole resistance in Candida albicans clinical isolates. Antimicrob Agents Chemother 2003; 47(4): 1220-7.

\section{Comment on this article:}

\section{$f(3)$ in $8+S$. P}

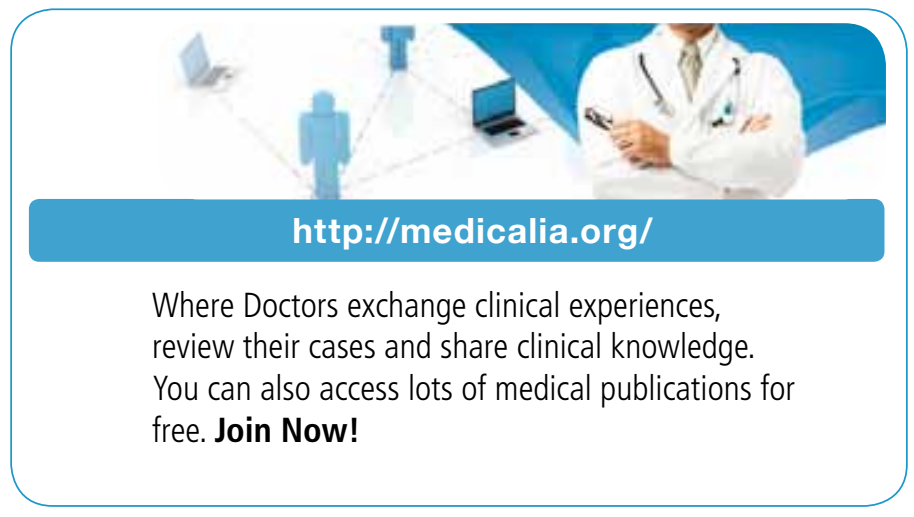

\section{Publish with iMedPub}

http://www.imed.pub

The Journal is an open access peer-reviewed journal that publishes scientific papers about all aspects of antimicrobials. The journal will publish original research articles, reviews, brief reports and case reports dealing with basic and clinical antibacterial agents, antiviral, antiprotozoals, antituberculuous, antifungal and antihelminthes agents.

All manuscripts must be prepared in English, and are subject to a rigorous and fair peer-review process. Accepted papers will immediately appear online.

The journal aims to advance the knowledge, attitude and the research of chemotherapy in the Arabic world in cooperation with international, national scientific and public societies as well as research centers with similar aims and objectives.

\section{Submit your manuscript here:} www.iajaa.org 